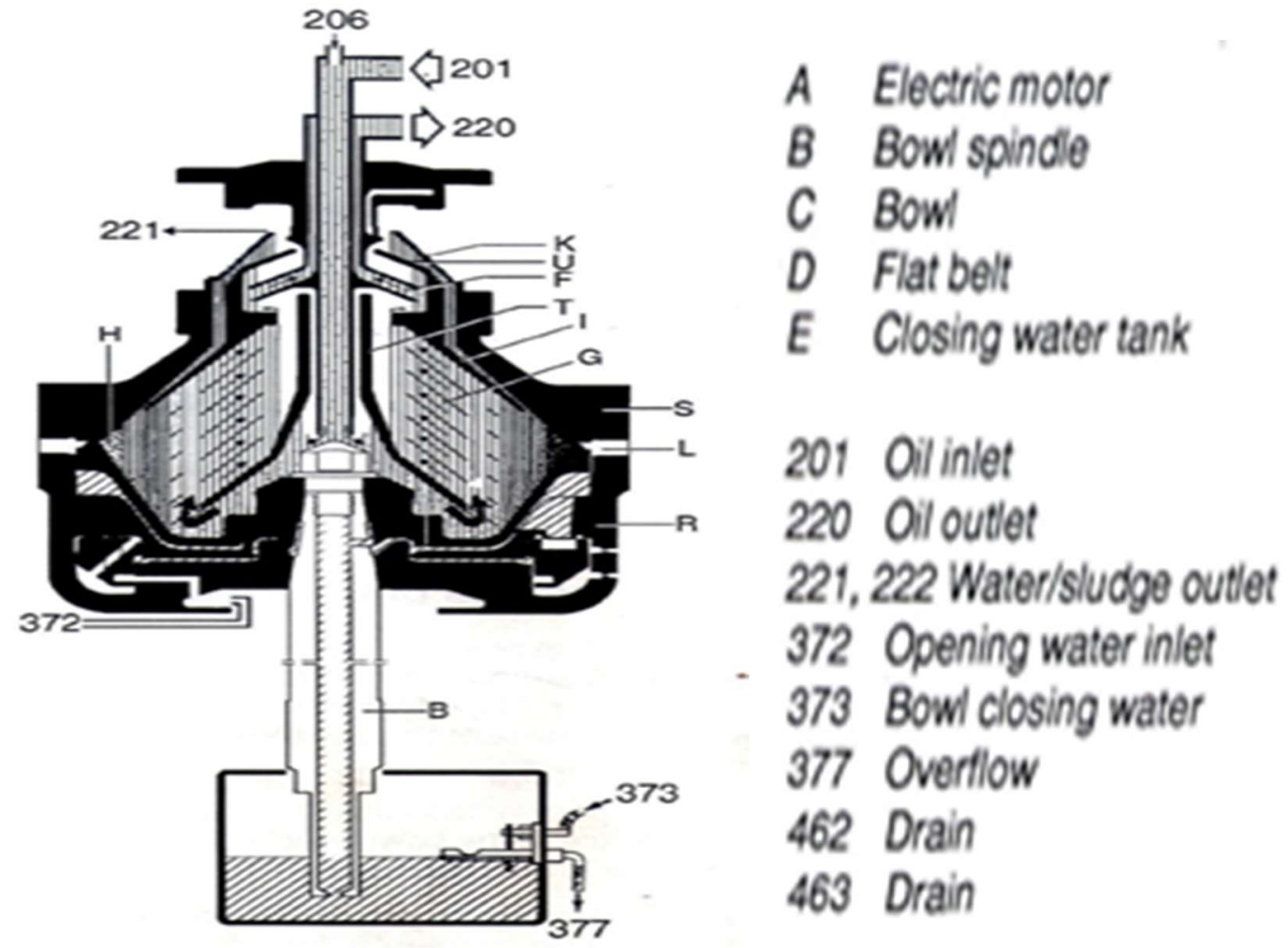

Gambar 7.Proses pemisahan minyak

\section{Pemecahan Masalah}

1. Pengaturan Supply minyak yang masuk kedalam purifier

Aliran minyak yang dipompakan oleh feed pump diatur pada bagian valve tekan pompa,sehingga jumlah minyak yang mengalir masuk ke dalam purifier mengalami penurunan volume.

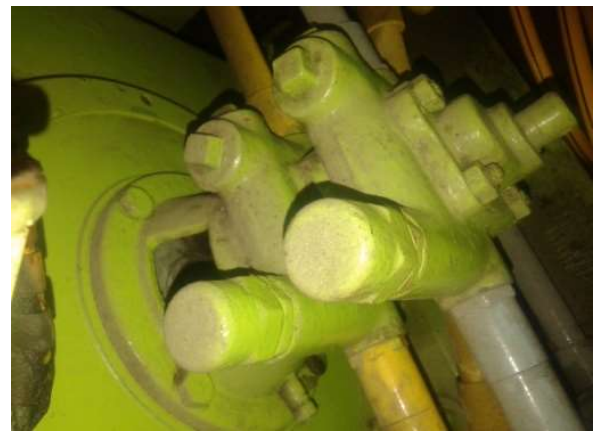

Gambar 8. Feed Pump 
- Cara mengatur aliran feed pump yang masuk ke purifier

$>$ Perhatikan tekanan pompa yang masuk ke dalam purifier dengan alat bantu manometer

$>$ Atur valve tekan pada feed pump

$>$ Selalu di amati pergerakan tekanan pada manometer dengan membandingkan keluaran minyak hasil pembersihan dari purifier

> Jika tekanan dan volume minyak terlalu kecil maka safety device low pressure pada keluaran purifier akan bekerja

Jika tekanan dan volume minyak terlalu besar maka safety device high pressure pada keluaran purifier akan bekerja,hal tersebut mengindikasi bahwa minyak hasil pembersihan purifier masuk kesistem overflow, dengan hal semacam tersebut sistem keamanan monitoring akan memproteksi mematikan sistem aliran minyak yang masuk kedalam purifier terbuang kedalam tangki minyak kotor / sluge

2. Pengecekan ukuran penggunaan diameter gravity disc

Pemilihan gravity disc

Gravity disc yang akan digunakan pada purifier terlebih dahulu harus diadakan pemilihan sesuai diameter ukuran yang akan diperlukan.dalam hal ini ukuran nya disesuaikan dengan pabrikan purifier tersebut.

Adapun petunjuk secara umum yang digunakan dalam pemilihan gravity disc yang cocok digunakan ,paling tidak harus memenuhi persyaratan antara lain

- Spesifik gravity ( berat jenis )

- Viscosity (kekentalan)

- Tabel seleksi gravity disc

- Suhu pemanasan

Dari persediaaan gravity disc yang tersedia,bisa dipilih sesuai ukuran diameter yang yang telah dihitung menggunakan tabel gravity disc yang tersedia sesuai instruction book purifier.

\section{Daftar Pustaka}

Instuction manual SELFJECTOR Mitsubishi kakoki kaisha,LTD

Instruction manual MMPX 404SGP-11 Separator Manual Alfa Laval

https://www.ehlersgmbh.com/produkt/messg eraete/viscositaet/viscotherm-v-92sensor-41/

https://marineengineeringonline.com/fueloil-viscosity-controller

http://www.sipheater.com/product/immersio n-heater/ 


\title{
PEMANFAATAN ENGINE LOG BOOK SEBAGAI SUMBER DATA UNTUK MELAKUKAN ANALISA KUANTITATIF KEHANDALAN DAN PERAWATAN PERMESINAN DI KAPAL.
}

\author{
Ratna Dwi K..$^{*}$, Eka Darmana ${ }^{2}$ \\ ${ }^{1}$ Program Studi T.Bangunan Kapal, Fakultas Kemaritiman, Universitas Ivet \\ Jl Pawayatan Luhur IV/17, Bendanduwur, Semarang \\ ${ }^{2}$ Program studi Teknika, Fakultas Teknik, Politeknik Bumi Akpelni Semarang \\ J1 Pawayatan Luhur II/17, Bendanduwur, Semarang \\ *Email : rtnkurniawan@gmail.com
}

\begin{abstract}
ABSTRAK
Melihat beberapa catatan harian kamar mesin (engine Log Book) di kapal, dapat diketahui bahwa perawatan permesinan yang dilakukan masih bersifat konvensional, perawatan dilakukan hanya saat komponen/sistem mengalami kegagalan atau saat kapal berlabuh. Berbagai metode perawatan dapat dilakukan untuk mencapai unjuk kerja dan biaya yang optimum. Dalam studi ini menawarkan analisa kehandalan secara kuantitatif dengan memanfaatkan data yang sudah ada dari engine log book, dengan sample perawatan pada sistem bahan bakar dari Main Engine. Sebagai output Analisa kuantitatif ini akan dapat diketahui nilai reliability dan unreliability sebagai fungsi waktu dan rata-rata waktu komponen akan mengalami kegagalan. Selain itu akan diketahui tren grafik laju kegagalan sehingga dapat diketahui apakah komponen dalam masa operasional atau sudah memasuki masa wear out / aus. Harapannya metode ini dapat diadopsi sebagai bahan pertimbangan dalam melakukan perawatan permesinan di kapal.
\end{abstract}

Kata Kunci : kehandalan/reliability, engine log book, maintenance

\section{PENDAHULUAN}

Dari data Komite Nasional keselamatan Transportasi (KNKT) Indonesia, pada tahun 2017 telah tercatat 34 kecelakaan kapal, meningkat $88 \%$ dari tahun 2016 yang hanya 18 kejadian. Kejadian kecelakaan terbanya dikarenakan kebakaran dengan jumlah 14 kasus, 6 kapal tenggelam, 6 kapal tubrukan, 6 kapal kandas dan 2 kecelakaan lainnya. jumlah tersebut termasuk tinggi, rata-rata hampir 3kejadian kecelakaan setiap bulannya. Dari biro klasifikasi, tertuang dalam volume I buku peraturan Biro Klasifikasi Indonesia, sebenarnya sudah mewajibkan pemeriksaan tahunan/Annual Survey, Survey Antara/Intermediate Survey, Maupun Pembaruan klas/Special Survey yang dilaksanakan setiap 5 tahun. Kegiatan pemeriksaan/survey tersebut dimaksudkan untuk menjamin keselamatan kapal beserta crew, penumpang, dan muatannya.

Perlu diketahui lebih dari 50\% kapal yang beroperasi di Indonesia merupakan kapal bekas, secara usia kebanyakan sudah berusia lebih dari 20 tahun. Bahkan PT Pelni, yang merupakan perusahaan pelayaran pemerintah, dari 24 kapal yang dimilikinya, hanya 1 kapal yang berusia 8 tahun, yang lain berusia diatas 30 tahun (data th 2014). Kecelakan disebabkan bebrapa faktor, faktor alam, faktor teknis dan faktor human error. Semakin tua usia kapal tentu memiliki kemungkinan terjadinya kecelakaan semakin besar. Jika melihat usia kapal, hal ini tentu sangat berkaitan erat dengan kegagalan yang disebabkan dari faktor teknis. Karena setiap komponen memiliki batas usia pakai/aus atau biasa diistilahkan wearout failure.

Kejadian kecelakaan kapal sebenarnya dapat diantisipasi dengan berbagai metode. Saat ini terdapat banyak metode analisa keselamatan kapal baik berupa kuantitatif maupun kualitatif. Analisa kuantitatif menggunakan data-data kegagalan/ kerusakan dari komponen dan atau sistem dalam rentang waktu tertentu untuk dimodelkan secara matematika sehingga 
dapat diketahui nilai dari laju kegagalan/ failure rate, laju perawatan/ repair rate, waktu operasional/ mission time, jadwal perawatan/ maintenance scedule dll. Sedangkan secara kualitatif dapat dilakukan dengan analisa pengaruh bentuk kegagalan (FMEA: Failure Mode Effec Analysis), Analisa pohon kegagalan (FTA: Fault tree Analysis) dll.

Setiap kapal dengan ukuran 200 GT akan memiliki buku catatan harian untuk deck dan mesin/ Engine log book. Buku catatan harian bagian deck berisi tentang kegiatan dan kondisi selama pelayaran, kegiatan dan keadaan/kejadian kapal saat berada di pelabuhan. Sedang Engine Log Book berisi cataan:

a) kondisi dan kinerja dari main engine, auxiliary engine, boiler dan permesinan lainnya.

b) Pemeriksaan-pemeriksaan yang dilaksanakan fihak berwenang

c) Kerusakan yang terjadi pada main engine, auxiliary engine dan permesinan lainnya yang berada di engine room

d) Perbaikan/ reparasi yang dilakukan dan spare part yang dipergunakan

e) Penggunaan bahan bakar, minyak pelumas dll

Data yang berasal dari engine log book yang berupa waktu operasi, perbaikan/reparasi yang telah dilakukan dan spare part yang telah digunakan, selanjutnya data yang dilakukan analisa dengan memodelkan secara matematik/statistik/analisa reliability secara kuantitatif maupun kualitatif, dari hasil analisa dapat disimpulkan berupa waktu/umur rata-rata komponen akan mengalami failure, waktu operasi dan jadwal perawatan untuk mencegah terjadinya kegagalan sistem.

Untuk memperjelas arah penulisan ini maka masalah yang akan dibahas adalah tinjauan kehandalan dari komponen sistem bahan bakar Main Engine dari KM Kawanua, menentukan laju kegagalan, waktu rata-rata terjadinya kegagalan, sehinga hasil tersebut dimaksudkan dapat digunakan sebagai bahan pertimbangan dalam melakukkakn kegiatan perawatan dan reparasi dan sebagai dasar dalam penggambilan keputusan/ tindakan yang akan diambil.

\section{DASAR TEORI}

Analisa kehandalan/ reliability merupakan turunan dari ilmu statistik, sehingga syarat utamanya adalah tersedianya data (dalam kasus ini data dari engine log book). Kehandalan berkaitan dengan distribusi probabilitas dengan pertimbangan bahwa semua komponen tidak akan mengalami kegagalan dalam waktu bersamaan, tetapi akan gagal pada waktu berbeda (time to failure ) mengiluti probabilitas kegagalan dari komponen.

Sehingga kehandalan dapat didefinisikan sebagai probabilitas suatu komponen/ alat untuk dapat berfungsi selama jangka waktu sesuai dengan yang diinginkan(R Billinton \& Ronald N.alan).

Untuk menggambarkan variasi laju kegagalan/failure rate sebuah komponen selama masa pemakaian, seringkali digunakan bathtub distribution, dengan kata lain distribusi data yang menyerupai bathtub (lihat gambar 1)

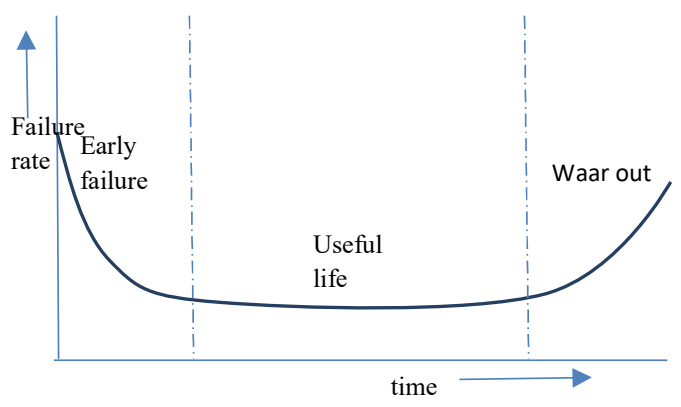

Gambar 1. Bentuk distribusi bathtub

Early failure: pada daerah ini terlihat grafik yang menurun, menunjukkan awal pemakaian, biasanya pemakaian awal mengalami kegagalan yg tinggi kemudian berjalannya waktu akan menurun hal ini disebabkan adanya cacat produksi, instalasi dll, olehkarenanya untuk produk baru misal kendaraan, peralatan elektronik diberikan garansi sampai waktu tertentujika ada 
kerusakan masih dalam tanggungan produsen.

Useful life : pada masa ini komponen memiliki laju kegagalan yang random/ acak.

Wear out : pada kurva terlihat naik ini berarti dengan berjalannya waktu laju kegagalan meningkat, hal ini berkaitan dengan komponen yang sudah mengalami korosi, oksidasi, aus karena gesekan dll.

Dari analisa kehandalan nantinya akan didapatkan model kurva diantara tiga kondisi tersebut diatas, sehinga dapat dijadikan pertimbangan dalam perawatan apakah akan menggantinya atau melakukan reparasi saja.

Dalam analisa kehandalan untuk persamaan (1) s/d (3)beberapa definisi/istilah yang harus difahami menurut Dr David J Smith :

(Failure (Kegagalan) : perubahan unjuk kerja (performance) dari spesifikasi yang telah ditentukan.

Failure Rate $\lambda(\mathrm{t})$ : Laju kegagalan per satuan waktu atau dengan kata lain jumlah kegagalan dalam rentang waktu tertentu.

ReliabilityR( $($ ) : Kehandalan yaitu kemungkinan komponen/ sistem melaksanakan fungsinya sesuai yang diharapkan.

Unreliability $\mathrm{Q}(\mathrm{t})$ : kemungkinan komponen/ sistem akan mengalami kegagalan/ bekerja tidak sesuai yang ditentukan.

Mean time to Failure(MTTF) : waktu ratarata hingga mencapai kegagalan, biasanya digunakan untuk komponen yang tidak dapat diperbaiki seperti bearing, transistor dll

Mean time between failure (MTBF) : hampir sama dengan MTTF namun biasa digunakan unutk komponen yang dapat di perbaiki/repair.

Failure rate $\lambda(t)$ : adalah kemungkinan terjadinya kegagalan dalam rentang waktu tertentu.

Reliability $\mathrm{R}(\mathrm{t})$ : adalah kemungkinan waktu survival / berfungsi dengan baik.

$$
\mathrm{R}(\mathrm{t})=1-\mathrm{Q}(\mathrm{t})
$$

Fungsi kehandalan $\mathrm{R}(\mathrm{t})$ merupakan komplemen dari Commulatif failure distribution function $\mathrm{Q}(\mathrm{t})$. Turunan dari $\mathrm{Q}(\mathrm{t})$ adalah failure density distribution atau dikenal $\mathrm{f}(\mathrm{t})$. Dimana:

$\mathrm{f}(\mathrm{t})=\frac{d Q(t)}{d t}=\frac{d R(t)}{d t}$

Atau $\mathrm{Q}(\mathrm{t})=\int_{0}^{t}(t) d t$

Dan $\mathrm{R}(\mathrm{t})=1-\int_{0}^{t}(t) d t$

Total daerah dibawah failure density function pada gambar 2. merupakan kesatuan yang ditulis sebagai berikut:

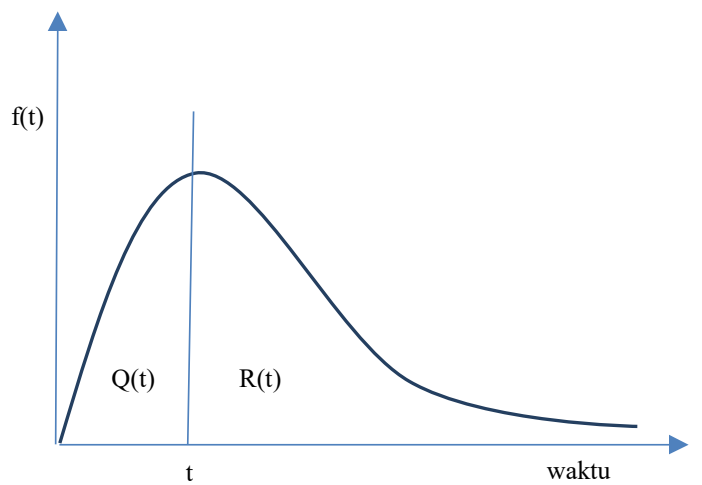

Gambar 2. Bentuk kurva density function

Nilai reliability, unreliability, MTTF dapat ditentukan dengan berbagai formula berbeda-beda tergantung dari kelompok distribusi data kegagalan/perawatan komponen yg terdapat di engine log book.

Sebagai contoh untuk data dengan distribusi log normal,reliability, unreliability dan MTTF didefinisikan sebgai berikut(formula $4 \mathrm{~s} / \mathrm{d} 7)$ :

$$
\begin{aligned}
& \mathrm{f}(\mathrm{t})=\frac{1}{t \sigma \sqrt{2 \pi}} e^{\left(\frac{(\ln t \quad)^{2}}{2 \sigma^{2}}\right)} \\
& \mathrm{R}(\mathrm{t})=\int_{t}^{\infty} f(t) d t \\
& \mathrm{Q}(\mathrm{t})=1-\int_{t}^{\infty} f(t) d t \\
& \mathrm{MTTF}=e^{\mu+\frac{1}{2} \sigma^{2}}
\end{aligned}
$$

Untuk data dengan kelompok distribusi Weibul 3, reliability, unreliability dan MTTF didefinisikan sebgai berikut (formula $8 \mathrm{~s} / \mathrm{d} 10)$ :

$$
\begin{aligned}
& \mathrm{R}(\mathrm{t})=e^{-\left(\frac{t+\gamma^{\gamma}}{\eta}\right) \beta} \\
& \mathrm{Q}(\mathrm{t})=1-e^{-\left(\frac{t+r}{\eta}\right)} \beta \\
& \mathrm{MTTF}=\gamma+\eta
\end{aligned}
$$


Dan untuk distribusi normal, gama, weibul 2, exponensial memiliki formila yang berbeda pula.

Nilai $\eta, \gamma, \beta, \mu$ dan $\sigma$ merupakan parameter yang didapat dari proses pengelompokan distribusi dalam hal ini dengan bantuan software weibul++.

\section{HASIL DAN PEMBAHASAN}

Hasil yang ingin didapatkan dari analisa kuantitatif ini adalah nilai kehandalan, seperti reliability $R(t)$, unreliability $Q(t)$, failure rate $(\lambda)$, dan mean time to failure (MTTF).

Analisa secara kuantitatif ini meliputi pengumpulan data dari engine log bookrentang yang berisi catatan waktu perawatan setiap saat yang dilakukan terhadap main enginelauxiliary engine dicatat, Analisa dilakukan untuk sistem bahan bakar sehingga dapat diketahui kehandalan untuk tiap komponen dari masing-masing sistem. Data berupa rentang waktu/time perawatan dicatat sebagai $\mathrm{T}$, T2,T3..dst sehingga kehandalan dapat dinyatakan dalam fungsi waktu $[\mathrm{R}(\mathrm{t})]$.

Langkah ke dua adalah menentukan jenis distribusi dari data masing masing komponen sistem bahan bakar padaMain Engine maintenanceuntuk sistem bahan bakar didapat kelompok/ jenis distribusi beserta parameternya dapat digunakan beberapa software seperti Minitab, weibul++ dll.Waktu perawatan tiap komponen memiliki kecenderungan distribusi berbeda-beda, hal ini ditunjukkan dengan waktu yang berubah-ubah. Untuk menguji distribusi dapat dilakukan dengan menggunakan beberapa metode seperti Maximum likelyhood estimate, sehingga dapat ditentukan bentuk reliability distribution function.

Dalam kasus ini penentuan kelompok distribusi menggunakan software weibul++, dan mengkasilkan kelompok distribusi beserta parameter . dari sampel data yang diginakan ternya ada duamacam distribusi untuk beberapa komponen seperti tercantum pada tabel 1 dan tabel 2:
Tabel 1. Komponen dengan distribusi weibul 3

\begin{tabular}{|l|l|l|l|}
\hline \multirow{2}{*}{$\begin{array}{c}\text { Kompone } \\
\mathbf{n}\end{array}$} & \multicolumn{3}{|c|}{ Parameter } \\
\cline { 2 - 4 } M/E valve & 1.1722 & $\eta$ & $\gamma$ \\
\hline Injektor & 1.2289 & 128.13 & -0.1599 \\
\hline
\end{tabular}

Tabel 2. Komponen dengan distribusi log normal

\begin{tabular}{|l|l|l|}
\hline \multirow{2}{*}{\multicolumn{1}{c|}{ Komponen }} & \multicolumn{2}{c|}{ Parameter } \\
\cline { 2 - 3 } & $\sigma$ & $\mu$ \\
\hline Cyl head & 1.471 & 5.08 \\
\hline Fuel pump & 1.364 & 5.06 \\
\hline Piston ring & 2.265 & 5.622 \\
\hline Fuel piping & 1.456 & 5.04 \\
\hline Strainer & 1.0686 & 4.378 \\
\hline
\end{tabular}

Nilai kehandalan tiap komponen dapat diketahui dengan menggunakan formula yang sesuai dengan jenis distribusi. Dari formula/rumus kehandalan tersebut dapat dihasilkan nilai kehandalan secara kuantitatif yang meliputi laju kerusakan komponen/failure rate.

Tabel 3. Prosentase dan failure rate pada 4026,00 jam operasi.

\begin{tabular}{|l|l|l|l|}
\hline Komponen & $\begin{array}{l}\text { Jml } \\
\text { kerusakan// } \\
\text { perawatan }\end{array}$ & $\begin{array}{l}\text { Kerusakan } \\
\text { per unit } \\
\text { waktu }\end{array}$ & $\%$ \\
\hline M/E valve & 133 & 0.31 & 41.95 \\
\hline Injektor & 93 & 0.021 & 29.34 \\
\hline Cyl head & 25 & 0.006 & 7.88 \\
\hline Fuel pump & 17 & 0.004 & 5.36 \\
\hline $\begin{array}{l}\text { Piston } \\
\text { ring }\end{array}$ & 4 & 0.0009 & 1.26 \\
\hline $\begin{array}{l}\text { Fuel } \\
\text { piping }\end{array}$ & 13 & 0.003 & 4.10 \\
\hline Strainer & 32 & 0.007 & 10.09 \\
\hline total & 317 & 0.0729 & \\
\hline
\end{tabular}

Dari tabel 3 diatas dapat diketahui laju kegagalan tertinggi adalah 0.031 pada komponen $M / E$ valve, diikuti oleh injektor dengan ini berarti sering mengalami perawatan atau bahkan fail/kegagalan.

Dengan menjumlahkan parameter $\eta$ dan $\gamma$ pada distribusi weibul 3 akan didapat waktu rata-rata komponen akan mengalami kerusakan (MTTF: Mean Time To Failure), sedang untuk distribusi log normal MTTF = $e^{\mu+0.5 \sigma^{2}}$ 
Tabel 4. Rata waktu untuk terjadinya kegagalan (MTTF).

\begin{tabular}{|l|l|}
\hline \multicolumn{1}{|c|}{ Komponen } & \multicolumn{1}{c|}{ MTTF (jam) } \\
\hline M/E valve & 86.3234 \\
\hline Injektor & 128.29 \\
\hline Strainer & 141.175 \\
\hline
\end{tabular}

Dari tabel 4, ditampilkan rerata waktu untuk sampai gagal pada 3 komponen dengan failure rate rangking 3 tertinggi dapat diketahui bahwa $M / E$ Valve yang memiliki Failure rate yang tertinggi memiliki nilai MTTF yang paling kecil., ini berarti valve tersebut harus menjadi perhatian untuk dilakukan perawatan atau dengan kata lain valve akan sering fail bila tidak dilakukan perawatan sebelum 86.32 jam operasi.

Untuk nilai kehandalan/Reliability $R(t)$ dan unreliability $Q(t)$ sebagai fungsi waktu (t)dapat ditentukan dalam tabel 5, dibawah ini:

Tabel 5. Nilai kehandalan dari 3 komponen dengan failure rate tertinggi

\begin{tabular}{|c|c|c|}
\hline $\begin{array}{c}\text { Kom } \\
\text { ponen }\end{array}$ & $R(T)$ & $Q(t)$ \\
\hline \multicolumn{3}{|c|}{ Distribusi Weibul 3} \\
\hline $\begin{array}{l}M / E \\
\text { valve }\end{array}$ & $e^{-\left(\frac{t+2.4}{83.923}\right)}$ & $1-e^{-\left(\frac{t+2.4}{83.923}\right)}{ }^{1.1722}$ \\
\hline $\begin{array}{l}\text { Injek } \\
\text { tor }\end{array}$ & $e^{-\left(\frac{t+1.599}{128.13}\right)}{ }^{1.228}$ & $1-e^{-\left(\frac{t+1.599}{128.13}\right)}{ }^{1.228}$ \\
\hline \multicolumn{3}{|c|}{ Distribusi log normal } \\
\hline \multirow[t]{2}{*}{$\begin{array}{l}\text { Strai } \\
\text { ner }\end{array}$} & \multicolumn{2}{|c|}{$\mathrm{R}(\mathrm{t})=\int_{t}^{\infty} \frac{1}{3.788} e^{\left(\frac{(\ln t-4.378)^{2}}{2.28)}\right)} d t$} \\
\hline & $\mathrm{Q}(\mathrm{t})=1-\int_{t}^{\infty} \frac{1}{3.78}$ & $e^{\left(\frac{(\ln t-4.378) 2}{2.28)}\right)} d t$ \\
\hline
\end{tabular}

$\mathrm{R}(\mathrm{t})$ dan $\mathrm{Q}(\mathrm{t})$ sebagai fungsi waktu ( $\mathrm{t})$ maka secara manual dapat ditampilkan dalam bentuk kurva/grafik, jika dengan softwareweibull ++ maka grafik secara langsung dapat ditampilkan. Dari grafik tersebut dapat juga dilakukan analisa, seperti berikut.

M/E Valve: (distribusi Weibul 3)

a) Kurva grafik kehandalan $\mathrm{R}(\mathrm{t})$ : akan mengalami penurunan sebelum 10 jam pertama kemudian kehandalannya akan mendekati nol (fail) pada 200 jam operasi b) Kurva Unreliability $Q(t)$ : berbanding terbalik dengan kehandalan, grafik ini akan meningkat hingga mendekati 100\%(benar-benar fail) 200 jam operasi.

c) Laju kegagalan (failure rate) pada 200 jam operasi, valve tersebut akan memiliki kemungkinan $0.02 \%$ kegagalan

Jika dibandingkan dengan kurva Reliability $R(t)$ dari injektor akan karakteristik yang berbeda, hal ini ditunjukkan dengan bentuk berbeda pula. Dari grafik dapat diketahui penurunan drastis pad permulaan hingga 120 jam operasi, kemudian menurun perlahan hingga mendekati nol pada 300 jam operasi. Untuk kurva laju kegagalan (Failure rate) laju kegagalan akan meningkat perlahan $0.01 \%$ pada 150 jam operasi, jika dilihat kurvanya yang naik perlahan dalam waktu relatif lama maka dapat disimpulkan bahwa injektor ini berapa pada kondisi akhir operasional/ memasuki wear-out.

Dengan metode yang sama, dengan melihat kurva Failure rate maka dapat diketahui kondisi komponen sebagai berikut:

Tabel 6. Kondisi komponen dilihat dari kurva failure rate

\begin{tabular}{|l|l|l|}
\hline Komponen & \multicolumn{1}{|c|}{$\begin{array}{l}\text { Kondisi } \\
\text { Komponen }\end{array}$} & $\begin{array}{l}\text { Ket kurva/ } \\
\text { cenderung }\end{array}$ \\
\hline M/E valve & $\begin{array}{l}\text { Awal Wear } \\
\text { out }\end{array}$ & Naik \\
\hline Injektor & $\begin{array}{l}\text { Awal Wear } \\
\text { out }\end{array}$ & Naik \\
\hline Cyl head & $\begin{array}{l}\text { Operasi } \\
\text { Normal }\end{array}$ & konstan \\
\hline Fuel pump & $\begin{array}{l}\text { Operasi } \\
\text { Normal }\end{array}$ & konstan \\
\hline Piston ring & $\begin{array}{l}\text { Operasi } \\
\text { Normal }\end{array}$ & konstan \\
\hline Fuel piping & $\begin{array}{l}\text { Operasi } \\
\text { Normal }\end{array}$ & konstan \\
\hline Strainer & $\begin{array}{l}\text { Operasi } \\
\text { Normal }\end{array}$ & konstan \\
\hline
\end{tabular}

Dengan mengambil contoh tabel 6 . komponen tersebut diatas dapat dijadikan acuan dalam mengambil tindakan/ kebijakan dalam melakukan perawatan, 
apakah cukup dengan perawatan rutin dengan menentukan jadwal perawatan masing-masing komponen berdasarkan MTTF

Keputusan dapat pula diambil dengan cukup melaksanakan perawatan atau harus mengganti komponen dengan dasar melihat bentuk grafik/kurva laju kegagalan (failure rate) apakah masih masa operasi (cenderung datar) atau sudah menunjukkan sudah berumur (cenderung naik), maka jika dipaksakan kemungkinan kerusakan akan semakin meningkat.

\section{KESIMPULAN}

Dari hasil analisa kuantitatif dapat diambil kesimpulan sebagai berikut:

a) Komponen pada sistem bahan bakar yang sering mengalami kerusakan/perawatan adalah $M / E$ Valve dan Injektor

b) Failure rate meningkat bahkan mengalami fase wear out pada komponen yang berhubungan langsung dengan ruang bakat (valve \& injektor), berarti komponen ini perlu dipertimbangkan adanya penggantian.

c) Untuk mendapatkan reliability system perlu dibuat reliability block diagram/ RBD untuk mengetahui hubungan masing - masing komponen dalam sistem apakah seri atau pararel.

d) Perlunya Analisa kualitatif, dengan menggunakan dasar bentuk kurva reliability. sebab penurunan kehandalan/peningkatan laju kegagalan terjadi pada waktu dan kondisi tertentu.

e) Perlu secara rinci dicatat dalam engine log book jenis kerusakan, lamanya perbaikan, jenis perbaikan/ penggantian sehingga jika dilakukan analisa dapat lebih dipertanggung jawabkan.karena jika dicermati, biasanya perawatan/ perbaikan dilakukan belum terencana tetapi dilaksanakan pada saat bongkar/ muat memanfaatkan waktu tidak berlayar.

f) Hasil dari analisa ini dapat digunakan sebagai dasar Reliability centered maintenance, sehingga jadwal bisa ditentukan untuk mengurangi terjadinya breakdown dan meningkatkan waktu pelayanan yang berarti secara ekonomi akan meningkatkan keuntungan.

\section{DAFTAR PUSTAKA}

Roy Billinton, Ronald N Allan, 1992, Reliability evaluation of engineering system, plenum press, new york

Dr David J Smith, 2002, Reliability, Maintainability and risk, Butterworth, Heinemann, 6 edition, oxford

Artana, Ketut Buda, 2005, Pendahuluan Kuliah Kehandalan Sistem, Handout Kuliah Kehandalan Sistem, Jurusan Teknik Sistem Perkapalan, ITS,

Eko Sasmito, Untung B, 2008, Analisa kehandalan sistem bahan bakar motor induk pada KM Leuser, Jurnal prodi Teknik Perkapalan, UNDIP 